\title{
Impact of a sensitization program on prescription order writing skills of second year MBBS students: a prospective study
}

\author{
Subhashini Ramakrishnan, Bhuvaneswari Krishnamurthy*, Umamaheswari Anbarasu
}

Department of Pharmacology, PSG Institute of Medical Sciences and Research, Affiliated to the Tamil Nadu Dr MGR Medical University, Chennai, Tamil Nadu, India

Received: 03 March 2020

Revised: 23 April 2020

Accepted: 27 April 2020

\section{*Correspondence:}

Dr. Bhuvaneswari Krishnamurthy,

Email: nandabhuvana@gmail.com

Copyright: (c) the author(s), publisher and licensee Medip Academy. This is an open-access article distributed under the terms of the Creative Commons Attribution Non-Commercial License, which permits unrestricted non-commercial use, distribution, and reproduction in any medium, provided the original work is properly cited.

\begin{abstract}
Background: Incomplete and erroneous prescriptions affect the effective management of patients. The undergraduates of today are the physicians of tomorrow. Hence, the need for inculcating good prescription writing practice from undergraduate level to improve quality of healthcare. The objective of this study was to assess the impact of a sensitization program on the effective prescription writing skills of second year MBBS students.

Methods: This prospective study was conducted between January and November 2017 among 149 second year medical students. The prescriptions by students were assessed prior to and after a sensitization program which emphasized on the importance of each component of the prescription, need for generic prescribing and rational use of drugs.

Results: After the sensitization program, there was significant improvement in mentioning of all components $(\mathrm{p}<0.05)$ except for route of administration, instructions, and health advise which were still deficient. The rationality in prescribing was analyzed by scoring vital drug related information on a scale of 12 . Majority of inscriptions (72\%; $\mathrm{n}=107)$ were rational after the program. There existed a weak positive correlation $(\mathrm{r}=0.15)$ between students' knowledge of drugs assessed by theory examinations and scores of prescriptions assessed in practical examinations.

Conclusions: The sensitization program served as an effective strategy in improving knowledge regarding every component of the prescription and enhanced the prescription writing skills at the undergraduate level. This could help prevent deficiencies in health care arising from errors in prescribing.
\end{abstract}

Keywords: Prescription writing, Medical students, Sensitization program, Rational prescribing

\section{INTRODUCTION}

The prescription is a written order from the physician to the pharmacist for dispensing medications and plays a key role in the management of patients. Proper decision making and appropriate transcribing are integral for an ideal prescription. ${ }^{1}$ Prescribing is a complex skill that requires a thorough understanding of the pathophysiology of a diagnosis, the pharmacology of an individual medication and how an individual's response may be affected by the pharmacokinetic and pharmacodynamic properties of a particular medication. ${ }^{3}$ There is no global standard for prescriptions and every country has its own regulations. The most important requirement is that the prescription be clear. It should be legible and indicate precisely what should be given. ${ }^{4}$ The parts of a prescription includes doctor and patient details, the superscription or heading with the symbol ' $\mathrm{R}$ ' or ' $\mathrm{Rx}$ ', which stands for the word recipe (in Latin, to take); the inscription, which focuses on the rational use of medicines; the subscription or directions for compounding the drug; and the signature of the prescriber. 
In recent years, medical researchers observe deficiencies in health care occurring due to many prescribing errors, which arise because of two factors. One could be due to decision making and the other due to defect in the art of writing prescriptions. The factors related to the former could be inappropriate prescription, irrational prescription, under prescribing, or over prescribing. Those related to the latter is purely because of inappropriately writing the prescription. ${ }^{5}$ Incomplete and erroneous prescriptions affect the well-being of patient adversely. Suboptimal or irrational prescription writing skills results in treatment failure, adverse clinical outcomes, wastage of our resources, and economical harm not only to the patients but also to the community. ${ }^{2}$

The second year MBBS Pharmacology curriculum includes training medical students in prescription writing. The students will incorporate this skill for the rest of their medical career. The results of a study of how well final years medical students performed in a prescribing exercise suggested that the root cause of prescribing errors was lack of a knowledge base that integrated scientific knowledge with clinical know-how. ${ }^{6}$ Many studies opine that once the newly qualified doctors are exposed to workplace prescription writing, they retrospectively feel that there was insufficient emphasis on practical aspects of writing prescription in undergraduate curriculum. ${ }^{15}$ Hence, prescription writing skill is an important target area for improvement. This study focuses on the prescription writing skills of Second MBBS students taking into consideration the completeness of the prescription, rational use of drugs and translational of theoretical knowledge to prescribing. This will enable to assess the prescription writing training provided by the department of pharmacology and determine the possible scope for improvement, if exists.

The objective of this study was to assess the prescription writing skills of second year MBBS students thereby reflecting the quality of learning pharmacology during their undergraduate period in the department of pharmacology.

\section{METHODS}

The present study was conducted in the Department of Pharmacology at PSG IMS \& R, Coimbatore. Based on convenient sampling, the sample size was determined to be 149 students doing second year MBBS. After obtaining IHEC approval and permission from the HOD, department of pharmacology, data collection was initiated. The study period was between January to August 2017.

Prescription Order writing is a skill that is a part of the second MBBS curriculum and students are trained in this skill during their practical session at the department of pharmacology. In addition to the regular classes on prescription writing, a sensitization program emphasizing the importance of each component of the prescription, rational use of drugs and their clinical relevance was held at the department using suitable clinical examples and scenarios. In addition to the completeness of the prescription, students were insisted to apply 'rational use of medicine concept'- right drug (in generic name - in capital letters) in the right dose for the right duration at the right frequency. Data was collected from internal assessment exam (IAE) papers that comprises of a section on prescription order writing for a clinical scenario. Data was analyzed and interpreted for improvement in quality of prescription writing skills.

\section{Statistical analysis}

Data of all the 149 students were included in the statistical analysis. Analysis was performed using IBM SPSS software (version 20 SPSS Inc., Chicago, IL, USA). All categorical data were represented by frequency distribution while descriptive statistics was used for numerical data. To determine statistical significance between the difference in proportions chi-square test was used. The statistical significance was set at $5 \%$ i.e., $\mathrm{p}<0.05$. Pearson correlation analysis was used to analyze the correlation between theory and prescription score.

\section{RESULTS}

Prescriptions of students were analyzed for completeness in prescribing $(n=149)$ (Figure 1) with reference to a standard format of prescription set by the department of pharmacology at PSGIMSR. In all the prescriptions 21 components as per the standard format were checked for presence or absence.

The basic demographic parameters of the prescription that included doctor's information and patient's information were initially analyzed. Before the sensitization program it was observed that doctor's information (doctor's name, qualification, register number, address) was provided by $125(84 \%), 122$ $(82 \%), \quad 110(74 \%), 133(89 \%)$ whereas after the sensitization program analysis revealed $147(99 \%), 136$ (91\%), 144 (97\%), 146 (98\%) of students had provided the same information respectively. This difference following the sensitization session was statistically significant $(p<0.05)$ for all components related to doctor's information (Table 1).

Patient's information (patient's name, age, sex, body weight) was provided by 122 (82\%), 136 (91\%), 131 (88\%), 97 (65\%) and following the sensitization program it was provided by $146(98 \%), 143(96 \%), 145(97 \%)$, $140(94 \%)$ of the students respectively (Figure $1 \mathrm{a}$ and b). After the sensitization program the improvement in all patient related components was statistically significant except for the mention of patient's age which was mentioned by most students even before the program (Table 1). 

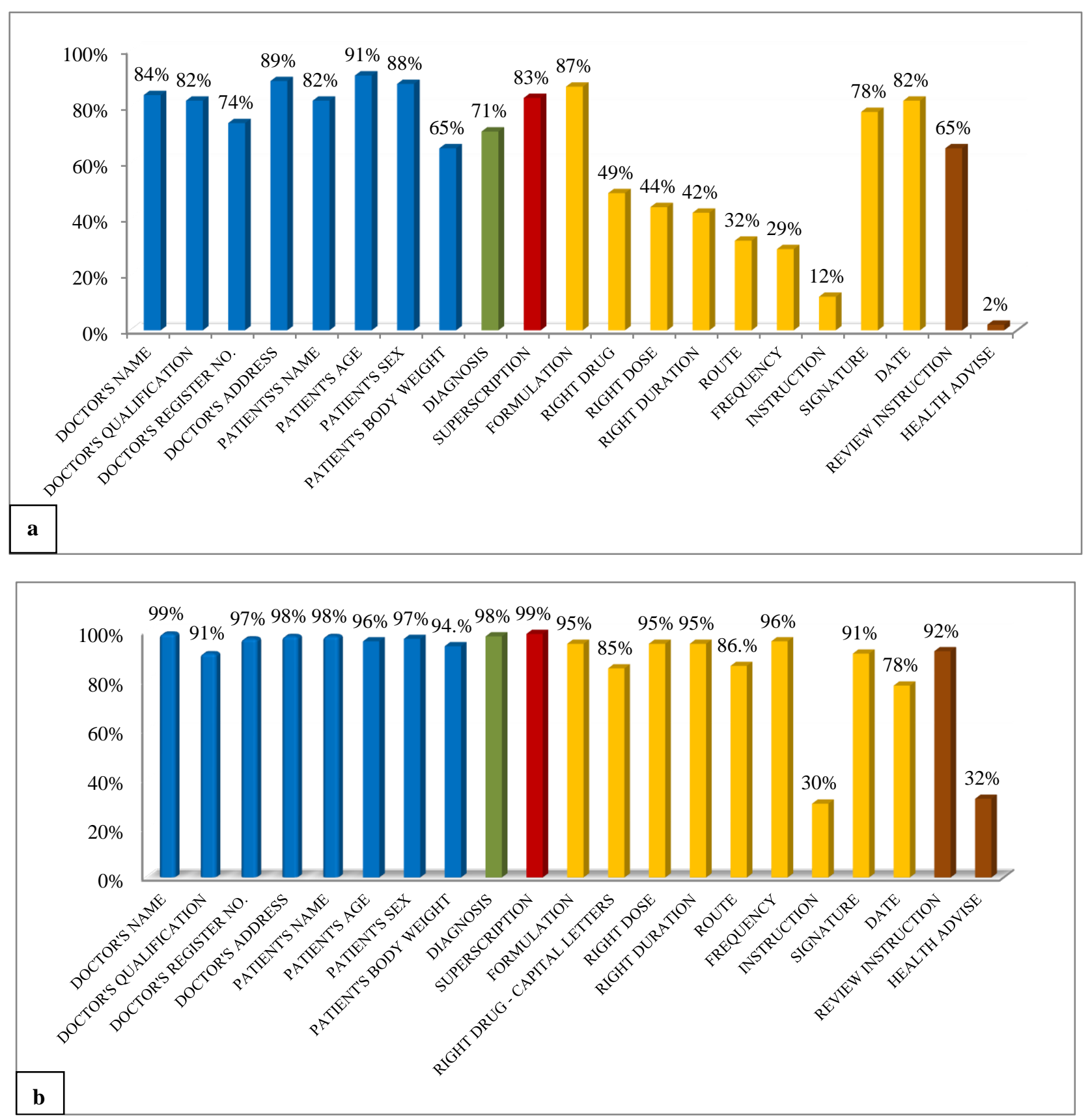

Figure 1: Percentage completion of prescription. (a) Before sensitization program and (b) after sensitization program.

On analyzing the prescriptions for presence of diagnosis it was found that before the sensitization program only $105(71 \%)$ had mentioned it, while the proportion increased after the program to 146 (98\%). This was a statistically significant improvement (Table 1). Rx symbol was provided by $124(83 \%)$ of students which also increased after the program to $146(98 \%)$ students and was analyzed to be statistically significant (Figure 1 and Table 1).

Analysis of the inscription part of the prescription containing drug related information and instruction (formulation, right drug - in capital letters, right dose, right duration, route of administration, frequency, instructions for intake, signature and date) revealed that prior to the program these information was provided by $130(87 \%), 73$ (49\%), 66 (44\%), 63 (42\%), 48 (32\%), 43 (29\%), 18 (12\%), $116(78 \%), 122(82 \%)$ respectively. Following the sensitization program the proportions increased to 142 (95\%), $127(85 \%), 142(95 \%), 142$ (95\%), 39 (86\%), 143 (96\%), 43 (30\%), 136 (30\%), 116 $(78 \%)$ of students respectively (Figure $1 \mathrm{a}$ and $\mathrm{b})$. There was statistically significant improvement with regard to all components of the inscription except for mention of date which had declined after the program, however this decline was not statistically significant (Table 1). 
Table 1: Completion of components of prescription before and after sensitization program.

\begin{tabular}{|c|c|c|c|c|c|}
\hline Component & $\begin{array}{l}\text { Before sensitization } \\
\text { program } \\
\mathbf{N}(\%)\end{array}$ & $\begin{array}{l}\text { After sensitization } \\
\text { program } \\
\mathbf{N}(\%)\end{array}$ & Difference & $\begin{array}{l}\text { Chi-square } \\
\text { value }\end{array}$ & Significance \\
\hline Doctor's name & $125(84$ & $147(99)$ & 15 & $21.480 * * *$ & $\mathrm{p}<0.0001$ \\
\hline Doctor's qualification & $122(82)$ & $136(91)$ & 9 & $5.150 *$ & $p<0.05$ \\
\hline $\begin{array}{l}\text { Doctor's register } \\
\text { number }\end{array}$ & $110(74)$ & $144(97)$ & 23 & $31.682 * * *$ & $\mathrm{p}<0.0001$ \\
\hline Doctor's address & $133(89)$ & $146(98)$ & 9 & $9.896^{* *}$ & $\mathrm{p}=0.0017$ \\
\hline Patient's name & $122(82)$ & $146(98)$ & 16 & $21.120 * * *$ & $\mathrm{p}<0.0001$ \\
\hline Patient's age & $136(91)$ & $143(96)$ & 5 & 3.054 & $\mathrm{p}=0.0805$ \\
\hline Patient's sex & $131(88)$ & $145(97)$ & 9 & $8.669 * *$ & $\mathrm{p}=0.0032$ \\
\hline Patient's body weight & $97(65)$ & $140(94)$ & 29 & $38.315 * * *$ & $\mathrm{p}<0.0001$ \\
\hline Diagnosis & $105(71)$ & $146(98)$ & 27 & $41.327 * * *$ & $\mathrm{p}<0.0001$ \\
\hline Rx symbol & $124(83)$ & $146(98)$ & 15 & $19.432 * * *$ & $\mathrm{p}<0.0001$ \\
\hline Formulation & $130(87)$ & $142(95)$ & 8 & $5.802 * *$ & $\mathrm{p}<0.05$ \\
\hline $\begin{array}{l}\text { Right drug - in capital } \\
\text { letters }\end{array}$ & $73(49)$ & $127(85)$ & 36 & $43.522 * * *$ & $\mathrm{p}<0.0001$ \\
\hline Right dose & $66(44)$ & $142(95)$ & 51 & $91.107 * * *$ & $\mathrm{p}<0.0001$ \\
\hline Right duration & $63(42)$ & $142(95)$ & 53 & $93.660 * * *$ & $\mathrm{p}<0.0001$ \\
\hline $\begin{array}{l}\text { Route of } \\
\text { administration }\end{array}$ & $48(32)$ & $39(86)$ & 54 & $89.505^{* * *}$ & $\mathrm{p}<0.0001$ \\
\hline Frequency & $43(29)$ & $143(96)$ & 67 & $142.212 * * *$ & $\mathrm{p}<0.0001$ \\
\hline $\begin{array}{l}\text { Instructions for } \\
\text { intake }\end{array}$ & $18(12)$ & $43(30)$ & 18 & $14.501 * *$ & $\mathrm{p}=0.0001$ \\
\hline Signature & $116(78)$ & $136(91)$ & 13 & $9.581 * *$ & $\mathrm{p}=0.0020$ \\
\hline Date & $122(82)$ & $116(78)$ & 4 & 0.742 & $\mathrm{p}=0.3889$ \\
\hline Review & $97(65)$ & $137(92)$ & 27 & $32.071 * * *$ & $p<0.0001$ \\
\hline Health advise & $3(2)$ & $47(32)$ & 30 & $47.360 * * *$ & $\mathrm{p}<0.0001$ \\
\hline
\end{tabular}

$* \mathrm{p}<0.05, * * \mathrm{p}<0.01, * * * \mathrm{p}<0.001$.

On analyzing for information on review and health advise it was observed that before the program only $97(65 \%)$ and $3(2 \%)$ of students respectively had mentioned it whereas after the program $137(92 \%)$ and $47(32 \%)$ of students respectively had provided relevant information (Figure 1). This improved was also found to be statistically significant (Table 1).

The rationality in prescribing was analyzed by scoring the 9 parameters included in the inscription that contains drug related information and instruction (formulation, right drug - in capital letters, right dose, right duration, route of administration, frequency, instructions for intake, signature and date). The scoring was done on a scale of 12 and percentage of the scores were calculated. Based on which rationality in prescribing was grouped as poor score 0\%-34\%; fair score 35\%-49\%; good score 50\%$79 \%$ and excellent score $\geq 80 \%$.

On analysis $3 \%$ of students $(\mathrm{n}=5)$ were grouped as poor, $1(1 \%)$ were grouped as fair, $36(24 \%)$ were grouped as good and $107(72 \%)$ as excellent. Among the $72 \%$ of students - $9 \%$ of the students $(\mathrm{n}=13)$ provided $100 \%$ complete prescription as per the standard format (Figure 2).

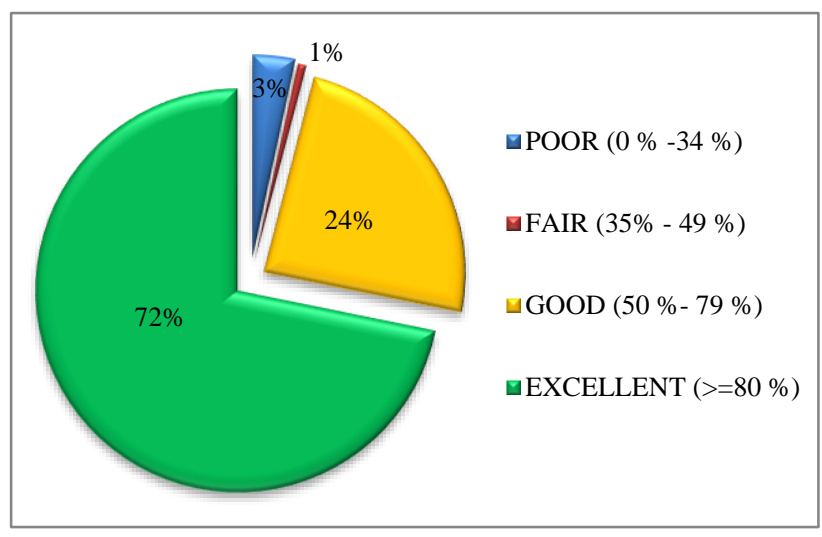

Figure 2: Inscription - rational use of medicine.

In order to assess the application of theoretical knowledge in writing a prescription, the theory score for a question related to the same diagnosis as that of the prescription audited was analyzed for correlation (Figure 3 ). The median prescription score (assessed for a maximum score of 12 ) was $10 \pm 6.4$ and the median theory question score (assessed for a maximum score of 30) was $10.7 \pm 6.4$. On analysis it was found that there was a weak positive correlation $(\mathrm{r}=0.15)$ between theory and prescription scores. 


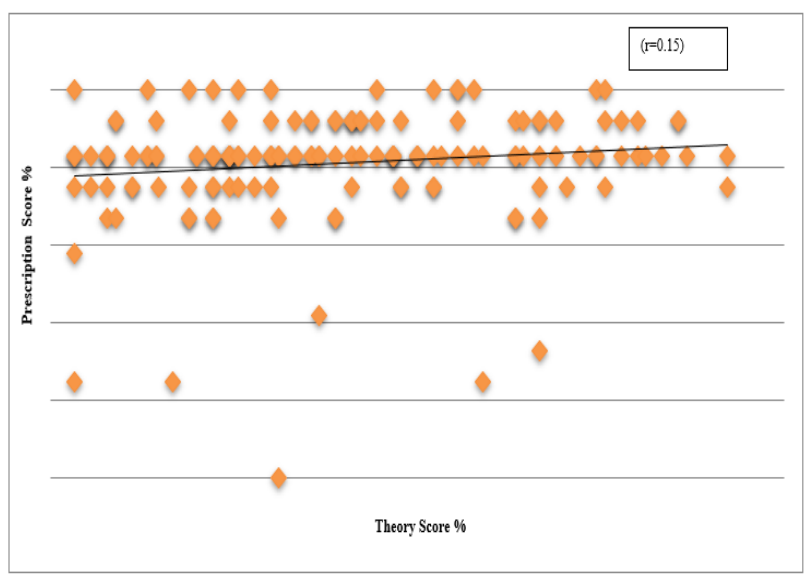

Figure 3: Correlation of theory and prescription score.

\section{DISCUSSION}

Prescribing drugs for common ailments are an important core competency of medical undergraduate. ${ }^{8,9}$ The existing medical undergraduate curriculum includes prescription training in the second year under pharmacology. Once poor prescribing skills are habitualized, changing them during postgraduate life is more difficult and usually requires different education strategies, which are expensive and time consuming. ${ }^{10,11}$

Babar et al, conducted a study on 206 prescriptions to assess the quality of prescription writing, patients name and age was present in 180 (87\%) and $115(55 \%)$ prescriptions respectively. ${ }^{12}$ In the current study we observed that the percentage of students completing the doctor's information (doctor's name, qualification, register number, address), patients information (patient's name, age, sex, body weight) and percentage of students mentioning diagnosis and superscription following the sensitization program was satisfactory with reference to the standards set by the department. A study conducted by James et al among third- and fourth-year medical students found that the $79.6 \%$ were able to correctly select the drugs, $69.4 \%$ and $68.2 \%$ were able to correctly mention duration and formulation of drug to be dispensed. ${ }^{13}$

In the current study it was observed that even after the sensitization program only $78 \%$ of students had mentioned the date which is a vital component of the prescription. In view of the fact that the prescriptions audited were those written in an exam setting rather than a clinical one, it is possible that the students have not attached due significance in mentioning it within the prescription as they had already mentioned it at the beginning on the exam paper.

Similarly, in spite of the program only $30 \%$ of students had mentioned instructions pertaining to drug intake (with respect to food or specific time of the day) and only
$32 \%$ of students had mentioned health advice which could be attributed to their beginning phase of clinical exposure. Probably more bedside observation of prescriptions with relevant instructions would positively reinforce the clinical importance of drug related instructions and health advises.

Although the percentage of students mentioning the right drug (in capital letters) and route of administration was above the expected standards, it can be further improved as it is the integral part of the prescription. In most instances students assumed route of administration to have been understood even without mentioning (e.g., Tablets are assumed to be taken only orally) which they probably would acquire by a deeper learning approach and better clinical exposure wherein they would be able to integrate learning with practical experience. ${ }^{14}$

Rational use of medicines is based on individualizing therapy and drugs, requiring an in-depth understanding of the mechanisms of drugs, their adverse effects and contraindications in addition to bedside learning. Among the parts of the prescription, the inscription containing drug related information reflects understanding by students of the rational use of medicine concept. The inscription scores and subsequent grouping showed that majority of students, $107(72 \%)$ where able to understand the rational use of medicine concept although there is still a scope for improvement.

The limitations of the study were that, this study was done to determine the quality of prescription orders written by II MBBS students who have limited clinical exposure. Since the prescription orders that are assessed in the exam are same as that taught in the practical session there may be a possibility that students memorized the prescription order format that is taught in the practical session.

\section{CONCLUSION}

The sensitization program served as an effective strategy in improving knowledge regarding every component of the prescription resulting in better completeness of prescriptions. The program also enhanced rational prescribing at the undergraduate level by promoting better correlation of theoretical knowledge with clinical scenarios. Such programs could help prevent deficiencies in health care arising from incomplete and erroneous prescriptions.

\section{Recommendations}

Sensitization programs coupled with bedside training of prescription order writing by virtue of its reinforcing nature could further improve the quality of prescribing in terms of completeness and rationality. Periodic monitoring of prescriptions of interns by clinical pharmacologists with feedbacks to interns might improve 
the quality of prescriptions issued by the fresh outgoing graduates.

\section{ACKNOWLEDGEMENTS}

My sincere thanks to the entire department of pharmacology at PSG IMS \& R, Coimbatore and the second year MBBS students of PSG IMS \& R without whom this study would not have been possible.

Funding: No funding sources

Conflict of interest: None declared

Ethical approval: The study was approved by the Institutional Human Ethics Committee - PSGIMS and R. Project no.17/332 dated 30th October 2017

\section{REFERENCES}

1. Akram A, Mohamad N, Meerah TSM, Zam ZR, Abdullah D. A pilot study-an action research to acquire clinical skill. Procedia Soc Behav Sci. 2012;60:236-40.

2. Kumar J, Shaik M. Appraisal of prescription writing skills of preclinical undergraduate students in a medical institute of Nepal. JCMS Nepal. 2010;6(4):713.

3. Aronson JK. A prescription for better prescribing. $\mathrm{Br}$ J Clin Pharmacol. 2006;61(5):487-91.

4. World Health Organization. How to investigate drug used in health facilities: selected drug use indicators. World Health Organization, Geneva; 1993.

5. Calligaris L, Panzera A, Arnoldo L, Londero C, Quattrin R, Troncon MG, et al. Errors and omissions in hospital prescriptions: A survey of prescription writing in a hospital. BMC Pharmacol Toxicol. 2009;9:9.

6. Boreham NC, Mawer GE, Foster RW. Medical students' errors in pharmacotherapeutics. Med Educ. 2000;34:188-93.
7. Thenrajan P, Murugan PR. Impact of patient-based teaching in improving prescription writing skills of II MBBS students. Int $\mathbf{J}$ Applied Basic Med Res. 2016;6(3):174.

8. Heaton A, Webb DJ, Maxwell SRJ. Undergraduate preparation for prescribing: the views of $2413 \mathrm{UK}$ medical students and recent graduates. $\mathrm{Br} \mathrm{J}$ Clin Pharmacol. 2008;66(1):128-34.

9. Kripalani S, Jones BJ, Katz MG, Genao I. A prescription for cultural competence in medical education. J Gen Intern Med. 2006;21(10):1116-20.

10. Grand LA, Hogerzeil HV, Ruskamp HFM. Intervention research in rational use of drugs: a review. Health Policy Plan. 1999;14(2):89-102.

11. Hogerzeil HV. Promoting rational prescribing: an international perspective. $\mathrm{Br} \mathrm{J}$ Clin Pharmacol. 1995;39:1-6.

12. Babar HS, Hussain S, Maqsood Z, Dad HA, Khan M, Rahman AA, et al. Adherence to prescription format and compliance with WHO core prescribing indicators. J Pharm Sci Res. 2014;6(4):195-99.

13. Khaja KA, Handu SS, James H, Mathur VS, Sequeira RP. Int J Clin Pharmacol Ther. 2005;43(9):429-35.

14. Maxwell S, Walley T. BPS Clinical Section Committee, Teaching safe and effective prescribing in UK medical schools: A core curriculum for tomorrow's doctors. $\mathrm{Br} \mathrm{J}$ Clin Pharmacol. 2003;55:496-503.

15. Heaton A, Webb DJ, Maxwell SRJ. Undergraduate preparation for prescribing: the views of $2413 \mathrm{UK}$ medical students and recent graduates. $\mathrm{Br} \mathrm{J}$ Clin Pharmacol. 2008;66(1):128-34.

Cite this article as: Ramakrishnan S, Krishnamurthy $\mathrm{B}$, Anbarasu U. Impact of a sensitization program on prescription order writing skills of second year MBBS students: a prospective study. Int J Basic Clin Pharmacol 2020;9:906-11. 